\title{
Field Training and Level of Stress in College Students: A comparison between Nursing Students who take care of ill Children and Early Childhood Education Students who Take care of Healthy Children
}

\author{
Dr. Siham M. Al- Momani PhD.Ed. MSN. RN. RM. \\ Associated Professor, Department of Allied Medical Sciences \\ Al Balqa' Applied University \\ Dr. Maram Fayez. Abdu. M.Ed \\ Lecturer Al-Balqaa Applied University (Jordan)
}

\begin{abstract}
Background: The fact that clinical experiences and field training are stressful to nursing students specially the beginners student is well understood. Significant of the study: This study would provide useful insights for faculties, preceptors; nursing and early childhood students involved in field training, and the implications for education, further research, and training support could be replanned accordingly. Method: Participants were asked to sign a covering letter which explains the participants right and demographic data. Participants who submitted all the surveys numbered 40 out of 50 students in early childhood education, and 40 out of 56 nursing students at AlBalqaa applied University. Almost all the students were female, between 19-22 years of age. Three longitudinal surveys were administered. Beck Depression Inventory Modified Arabic Version scale was used to measure stress level. Results: Overall stress level for both groups of students were high in the three round of surveys, more than one-third of the students were stressed before admitted to their assigned training fields two weeks after the training and at the end of the training period. The survey which was carried out after two weeks of training got the highest degree of stress level, clarified from the highest standard deviation of all surveys reading.
\end{abstract}

Keywords: Reality shock, Stress, stress reactions, field-clinical training, nursing students, early childhood education students.

\section{INTRODUCTION}

Stress can be regarded as a psychological threat, in which the individual perceives a situation as a potential threat (Day and Livingstone 2004). Stress results from the interaction between stressors and the individual's perception and reaction to those stressors (Misra and McKean 2000).

Academic stress among college students has been a topic of interest for many years. Seyedfatmi , Tafreshi \& Hagani (2007) identified significant changes in living conditions, the novel demands of the college academic environment and the large change in social surroundings are just a few of the potential sources of stress for college students. Stress and the identification of potential stressors among nursing students have received much attention in the literature. Nursing students have the same academic stressors as other college students, such as examinations and assignments. In addition, nursing students experience a clinical component, which is highly stressful. Students have a large amount of preparatory work before their clinical assignments. They often must travel long distances to clinical sites and use highly 
technical equipment. In addition, they must perform procedures that can cause harm to their patients, thus enhancing their fear of making mistakes. Studies indicate that nursing students may be more prone to stress than other students (Evans \& Kelly 2004).

Marlene Kramer (1974) described this changing perspective from the ideal school values to the working world values as reality shock. Kramer defines reality shock as the total social, physical, and emotional response of a person to the unexpected, unwanted, or undesired, and in the most severe degree, to the intolerable. It is the startling discovery and reaction to the discovery that school -world values conflict with work-world values (Kramer 1974).

Many studies on stress in nursing have attempted to measure the effects of such stress on nurses' health and well-being. There appears to be general agreement that the experience of work-related stress generally impaired the quality of nurses' working lives, increases minor psychiatric morbidity, and may contribute to some forms of physical illness, with particular reference to musculoskeletal problems, stress, and depression (Smith \&Leggat 2007; Watson et al 2006). So, the fact that clinical experiences and field training are stressful for nursing students is well understood and the newly admitted nursing students have been found to be more stressful (Nicholl and Timmins 2005), but there are no studies examined the stress experienced by associate nursing students taking care of early childhood ill children in comparison to the stress experienced by early childhood education students taking care of early childhood healthy children, and it is necessary to broaden the focus of this especially when the early childhood education admitted as a new specialty in Al-Balqaa Applied University, taking care of the nursing students and the early childhood education students that shared the goal of providing a comprehensive care focusing on helping children achieve their optimum health potentials.

Therefore, this study assessed the level of stress experienced by college students when admitted to field training, and compared between the nursing Students' who take care of early childhood ill children and early childhood education students who take care of healthy children.

\section{THEORETICAL FRAMEWORK}

The person-environment model (Lazarus 1991) of stress cognitive appraisal and coping was used in understanding stress among students. Stress is viewed as a relationship (transaction) between individuals and their environment. According to person-environment model, when students judge their education and field training as a challenge, stress can bring them a sense of competence and an increased capacity to learn. When education and field training is seen as a threat, stress can elicit feelings of helplessness and loss (Lazarus 1991).

\section{Study hypothesis}

\section{METHOD}

This study assessed the level of stress experienced by college students when admitted to field training, and compared between the nursing Students' who take care of early childhood ill children and early childhood education students who take care of healthy children, therefore, hypothesized that:

1. Level of stress experienced by nursing students who take care of early childhood ill children are higher than the level of stress experienced by early childhood education students who take care of healthychildren during their field training. 


\section{Study design}

Longitudinal design, a stress level assessment survey assessed the level of stress experienced by the participants before admitted to clinical practice, giving the same stress assessment survey two weeks after their experience started, and the same stress assessment survey toward the end of the semester 16 weeks later before the final exam period were repeated (Polit \& Beck, 2017).

\section{Population}

The eligible population for this study was all the nursing students, and the early childhood education students booked for field training course.

\section{Sample}

Convenience sample. 106 students agreed to participate. Eighty students (75.4\%) of the participants completed the study requirements. Exclusion criteria for participation included (a) students who had been referred previously for psychological consultation $(n=1)$ of the early childhood education student, (b) student who has got 10 and more points in the first assessment ( $\mathrm{n}=20)$, and (c) students who were partially committed to the study requirements (did not complete the three assessment survey $(n=5)$ four of them were early childhood education students. The sample includes forty nursing students and forty early childhood education students.

\section{Instruments}

\section{Demographic Questionnaire}

Student's indicated his/her age, educational status, marital status, occupation if there is, living condition (living separately or with the family), and total income of the family, number of family members and their ages.

\section{Arabic Language Modified Version of Beck Depression Inventory - 1(BDI-1)}

An 18- item self-report measure of depressive symptoms. Respondents rated on a 3-point scale ranging from 0 to 2 , the severity of symptoms? Sum scores $<9=$ normal status, $10-18=$ mild level, $19-27=$ moderate level, and $>28=$ severe level of depression. The validity and reliability of the modified Arabic version of the scale have been confirmed (Sarhan, $W$ et al 2001). In this study, internal reliability for the total scale was .86. The alpha coefficient was .84 by the control group report and .88 by experimental group report.

\section{Procedure}

All the study procedure accepted as part of the field training course requirements. No permission other than the student's agreement was required. Each group of the students during their orientation to the field training course was oriented to the study purpose and requirement by their assigned clinical teachers.

Students who agreed to participate signed a consent form ensuring the anonymity and the liability to continue or stop the procedures according to the student's preference, and they were given the survey questionnaire to be filled and returned within two hours.

\section{Data collection / analysis}

Levels of stress for both groups were evaluated as (baseline) reading one week before the students started their field training, and reevaluated using the same scale two weeks post of first assessment and toward the end of the semester before the final examination period. The justification for these time frames came from time constraints on the academic course 
completion. The data were analyzed with the SPSS statistical package. Descriptive statistics were also examined. An alpha level of 0.05 was used for all statistical tests.

\section{RESULTS}

Independently of the type of comparison made, The SPSS values were not statistically significant. None of the demographic/college specialty variables were significantly correlated with student's stress symptoms.

Eighty students (75.4\%) of the potential participants completed the study requirements. A (266) questionnaire completed by the participants, over three rounds, participants were asked to sign a covering letter which explains their right to continue or withdrawal from the study at any time and includes demographic data. Forty Nursing students and forty early childhood education students, representing $71.4 \%$ and $80 \%$, respectively, of potential respondents completely filled the three surveys, and participated in the study. Fifteen (15) Nursing students, and 6 early childhood education students, $19.8 \%$ of the total potential participants they have got a score of 10 and more in the (BDI) in the first assessment before they have been admitted to the practice area), so they were excluded from the sample. All the participants were female 19-22 years of age. Table 1shows total participants result in the three surveys. As far as the students who got 10 points and more in the first assessment survey was excluded from the study sample the stress level among the participants was Zero. The total participants mean Modified BDI-1 in phase two and phase three was (37.5\%, 36.25\%) respectively.

\begin{tabular}{lll}
\hline Table 1: Prevalence of (BDI) & Score of $\mathbf{1 0}$ and above in the total sample \\
\hline Score of $\mathbf{1 0}$ and above & Frequency (Total No\# 80) & Percent \\
\hline Before Admission to practice & 00 & 00 \\
After 2 weeks & 30 & $37.5 \%$ \\
At the end of practicum & & $36.25 \%$ \\
\hline (16 wk latter) & 29 &
\end{tabular}

Table 2 shows the Prevalence of (BDI) Score of 10 and above (which indicate the number of stressful students)

Table 2: Prevalence of (BDI) Score of 10 and above Comparison between the two groups

\begin{tabular}{|c|c|c|c|c|}
\hline \multirow{3}{*}{ participants } & & \multicolumn{3}{|c|}{ Prevalence of (BDI) Score of 10 and above } \\
\hline & & \multirow{3}{*}{$\begin{array}{l}\text { Before Starting Trainin } \\
\text { g Experience }\end{array}$} & \multirow{3}{*}{$\begin{array}{l}\text { Two wk } \\
\text { s } \\
\text { After } \\
15\end{array}$} & \multirow{2}{*}{$\begin{array}{c}16 \text { wks after } \\
\text { (end of training ex } \\
\text { perience) }\end{array}$} \\
\hline & & & & \\
\hline & Count & & & 16 \\
\hline Nursing Students (No\#40) & Percent & $0 \%$ & $37.5 \%$ & $40 \%$ \\
\hline Early Childhood Education S & Count & 0 & 15 & 13 \\
\hline tudents. (No\#40) & Percent & $0 \%$ & $37.5 \%$ & $32.5 \%$ \\
\hline
\end{tabular}

Table 3 shows the Prevalence of (BDI) Score of 19 and above ( which indicate the number of depressed students 
Table 3: Prevalence of (BDI) Score of 19 and above.

Comparison between the two groups (Depressed)

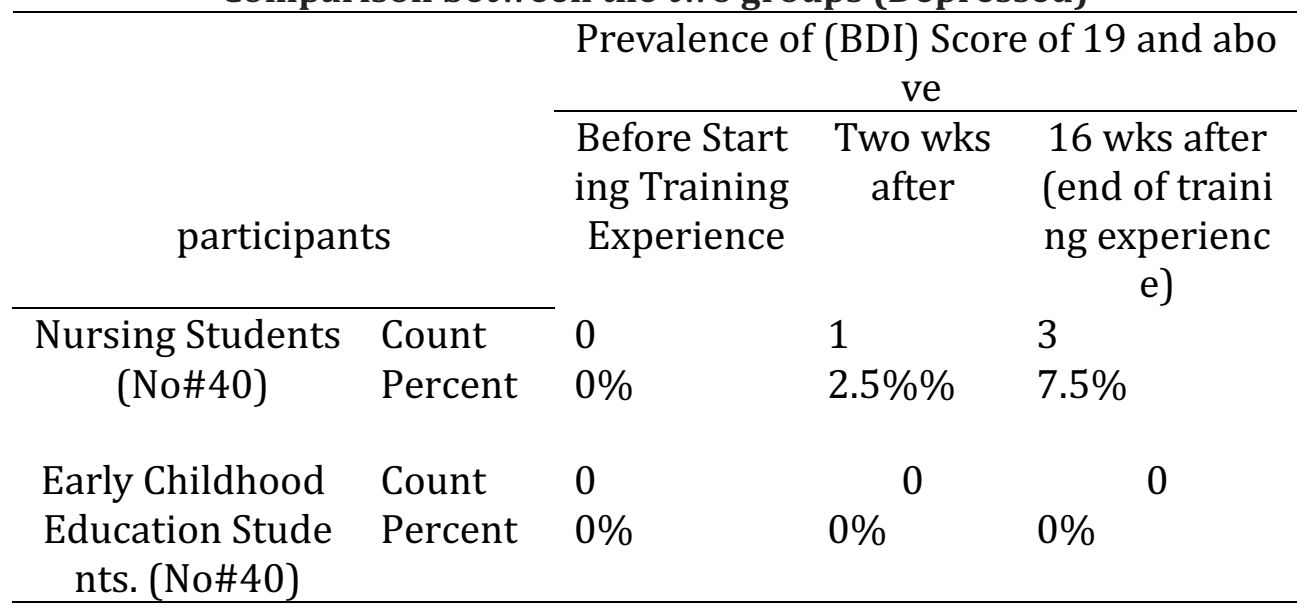

\section{DISCUSSION}

The results of this study found as clarified from the findings, that proportionally large number of students in both specialties' involved in this study were excluded from the study because they were already having a level of stress which exceeded the normal level according to the tool used. This finding supports the findings of (Misra and McKean 2000) who confirmed that the excessive homework, unclear assignments, uncomfortable classrooms, relations with faculty members and time pressures are leading causes of stress among college students.The study findings indicated the high level of stress experienced by the nursing students even if the level is not statically significant. These findings support the findings provided by (Nicholl and Timmins 2005), when they concluded that the nursing students are more exposed to stressors. The data provided important information about the client as a related stress factor, if we look at the level of stress which was higher among the nursing students. This finding supports the findings of (Evans and Kelly 2004) who confirmed that the clinical practice is one of the sources of stress for the nursing students. Also, the findings of this study provide evidence of the potential stress induced by the field training, 37.5\% of both groups were stressful and anxious two weeks after starting their clinical training, which supports the findings of (Shields 2001). The more stress experienced by the nursing students either in severity or percentage could be related to their patient's conditions, pain or death. These findings support the findings of (Smith and Leggat 2007) who concluded that the stressful events experienced by the nursing students might lead to malpractices, smoking and drinking habits.

\section{CONCLUSION}

Based on the assumption of this study "The Level of stress experienced by nursing students who take care of early childhood ill children are higher than the level of stress experienced by early childhood education students who take care of healthy children during their field training". Results indicated that the stress experienced by nursing students who take care of early childhood ill children are higher than level of stress experienced by early childhood education students who take care of healthy children during their field training, but not to the level that is statistically significant. The results provide evidence that the stress could be experienced by all college students, and illustrated the need to assess and evaluate the sources of stress for college students regardless of their specialty and level of education. Academic and field training related stressors need to be addressed by college faculties from the perspective that there may be ways of reducing the college students stress through emotional and psychosocial support, providing the students with information regarding stress signs and symptoms, stress management strategies, time management strategies, and faculties contribution to affect positive evidence based change in their settings. 
The small convenience sample, the self-report surveys which could prohibit the generalization of the study findings, and accepted as a potential limitations of the study. A mixed method for evaluation of the students' stress reaction pre and post starting their field training and field practice as an assessment of the students' through observational tool used could improve the Validity and reliability of the results.

\section{ACKNOWLEDGEMENTS}

Kind regards and thankful thoughts for the participants for their participation and collaboration in the study.

\section{References}

Chiang L., Hunter C. D and Yeh, C. J. (2004) Coping attitudes, sources, and practices among Black and Latino college students. Journal of Adolescence. 39(156): 793-815.

Day, A. L., Livingstone H, A.(2004) Gender differences in perceptios of stressors and utilization of social support among university students. Canadian Journal of Behavioral Science. 35(2): 73-83.

Evans W., Kelly B. (2004) Pre-registration diploma student nurse stress and coping measures. Nurse Education Today, 24(6): 473-482.

Kramer . M. (1974) Reality Shock. Saint Louis, ISBN 13:9780801627415

Lazarus, R. S and Folkman, S (1984). Stress, Appraisal, and Coping. New York: Springer.

Lazarus, R. S (1991). Emotion and Adaptation. New York: Oxford University Press.

Misra R., and McKean M. (2000). College student,s academic stress and its relation to their anxiety, time management, and leisure satisfaction. American Journal of Health Studies. 16(1): 41-51.

Nicholl H. and Timmins F. (2005). Program-related stressors among part-time undergraduate nursing students . Journal of Advanced Nursing. 50(1): 93-100.

Polit, D.F. and Beck, C.T.( 2017). Nursing Research:Generating and Assessing Evidence for Nursing Practice (10th ed). Philadelphia, PA: Wolters Kluwer.

Sarhan, W., Khateeb, J., Habashneh, M (2001). Behaviors (3) Depression ( 1st ed). Majdalawi. ISBN 9957-02-066-8.

Tafreshi M., and Hagani H. (2007). Experienced stressors and coping strategies among Iranian nursing students . BioMed Central Nursing Journal. 6(11): doi: 10. 1186/1472-6955-6-11.

Shields N. (2001) Stress, active coping, and academic performance among persisting and nonpersisting students. Journal of Applied Biobehavioral Research. 6(2): 65-81.

Smith D. R., and Leggat P, A. (2007). Tobacco smoking habits among a complete cross-section of Australian nursing students. Nursing and Health Sciences. 9(2): 82-89.

Watson H., Whyte R., Schartau E and Jamieson E. (2006). Survey of student nurses and midwives: smoking and alcohol use. British Journal of Nursing. 15(22): 1212-1216. 